\title{
O estranhamento causado pela deficiência: preconceito e experiência
}

\author{
Luciene M. da Silva \\ Universidade do Estado da Bahia, Programa de Pós-Graduação Educação e Contemporaneidade
}

\section{Introdução}

Tomando como base a análise de Horkheimer e Adorno (1985) sobre o anti-semitismo, encontramos elementos notórios que elucidam a dinâmica do preconceito como atitude hostil direcionada a objetos definidos a partir de generalizações, informações imprecisas e incompletas. Essa reflexão tem como referência a experiência traumática vivida pelos autores na Europa sob o terror fascista que, a despeito de ser um fato datado historicamente, deixa seu rastro visível no atual panorama sociopsíquico, com sinais evidentes de mal-estar, vandalismo e vida precária, configurando um terreno fértil para a reincidência da barbárie. O preconceito, para esses autores, incorpora fenômenos contemporâneos, resultantes das relações sociais cada vez mais impeditivas para a reflexão sobre a própria impotência diante de uma ordem social que diferencia pela estigmatização. Numa sociedade que impõe renúncias e sacrifícios, que enrijece o pensamento dadas as condições de sobrevivência num contexto de privações determinadas por relações desiguais, de apropriação concentrada dos bens ma- teriais e simbólicos, o preconceito torna-se um elemento presente e freqüente no processo de conhecer, restringindo-se, por conseguinte, à mera apreensão do imediato. As atitudes de preconceito desenvolvem-se no processo de socialização que é fruto da cultura e da sua história: "Como tanto o processo de se tornar indivíduo, que envolve a socialização, quanto o do desenvolvimento da cultura têm se dado em função da adaptação à luta pela sobrevivência, o preconceito surge como resposta aos conflitos presentes nessa luta" (Crochik, 1996, p. 11).

Nesse contexto, cabe enfatizar o elemento psicológico como determinante na adesão ou vinculação do indivíduo aos valores que contradizem seus próprios interesses. O ajustamento à sociedade dá-se pela incompreensão de que podemos constituir-nos como seres autônomos capazes de realização dos objetivos além dos puramente imediatos. A saída vislumbrada é o ajustamento à sociedade tal qual nos é apresentada, pela impossibilidade de negar o real e, assim, refletir sobre os condicionantes e a própria constituição do indivíduo. Considerando as necessidades do indivíduo para controlar suas projeções es- 
pontâneas, que estariam incorporadas no seu sistema psíquico de forma automatizada, o que parece ser patológico, segundo a análise do anti-semitismo feita por Horkheimer e Adorno (1985, p. 177), é a impossibilidade para refletir não apenas o objeto, como também a si próprio: "Ele dota ilimitadamente o mundo exterior de tudo aquilo que está nele mesmo; mas aquilo de que o dota é o perfeito nada, a simples proliferação dos meios, relações, manobras, a práxis sinistra sem a perspectiva do pensamento".

O preconceito materializa um possível efeito do encontro entre pessoas, quando são acionados mecanismos de defesa diante de algo que deve ser combatido por constituir-se numa ameaça. Num mundo em que o medo prevalece, indicando um perigo objetivo, e, ao mesmo tempo, não possibilita sua elaboração, as formas de organização social seguem negando, de forma renovada, a diferença. A cultura, que se converteu em mercadoria, renuncia a ser liberdade do espírito para ser um veículo da alienação e domesticação, bloqueando gradativamente o pensamento crítico que tornaria viável desvelar os sentidos da sobrevivência constantemente ameaçada e que determinam os comportamentos hostis. O esclarecimento como desencantamento do mundo seguiu uma trilha determinada pela intenção explícita de rompimento da natureza, de dominação do mundo: "a essência do esclarecimento é a alternativa que torna inevitável a dominação" (Horkheimer \& Adorno, 1985, p. 43). Tal metamorfose se fez pela objetividade, que a tudo busca assemelhar, induzindo à estranheza irracional. $\mathrm{O}$ cientificismo daí decorrente se iguala ao mito, porque enrijece seu objeto na busca de apoderar-se dele para classificar, nomear, calcular até torná-lo nulo, a custo de suprimir também o sujeito que intenciona conhecer, e que, dessa forma, se vê desprovido da possibilidade de discriminar. Diante do novo, do irreconhecido, temos a propensão a generalizar utilizando estereótipos e analogias substitutivas das possíveis problematizações: são simplificações que respondem à demanda imediata do pensamento, valendo-se de conteúdos e juízos de valor incorporados, conforme a condição e posição na hierarquia so- cial. Quanto a isso, explicam Horkheimer e Adorno (1985, p. 188):

No mundo da produção em série, a estereotipia - que é seu esquema - substitui o trabalho categorial. O juízo não se apóia mais numa síntese efetivamente realizada, mas numa cega subsunção. Se, numa fase histórica primitiva, o julgar consistia num rápido discriminar capaz de desfechar sem hesitação a seta envenenada, nesse meio tempo a prática da troca e a administração da justiça fizeram seu trabalho. [...] Na sociedade industrial avançada ocorre uma regressão a um modo de efetuação do juízo que se pode dizer desprovido do juízo, do poder de discriminação.

O estereótipo oferece pronto o conteúdo reduzido e vazio concedido pela pseudocultura bloqueadora da possibilidade de pensar a realidade de forma dialética, como afirma Crochik (1997, p. 19): “A obrigatoriedade da certeza traz a necessidade de respostas rápidas, colocadas em esquemas anteriores, que se repetem independentemente das tarefas às quais se destina, gerando uma estereotipia nas ações e procedimentos".

Para isso, a indústria cultural subordina as realizações humanas à fórmula que se explica pela repetição incessante, cujas inovações, se assim podem ser denominadas, são procedimentos de aperfeiçoamento da produção em série de qualquer coisa, desde objetos até formas ou fórmulas de pensar. Segundo Adorno (1995b, p. 144), "na indústria, o indivíduo é ilusório não apenas por causa da padronização do modo de produção. Ele só é tolerado na medida em que sua identidade incondicional com o universal está fora de questão". O indivíduo transformado em consumidor dos produtos oferecidos pela indústria cultural vê-se enfraquecido diante da mesmice que lhe é oferecida e, na seqüência, é induzido a reações massificadas, propícias à reincidência de práticas preconceituosas.

O preconceito, que é uma disposição individual, mas não apenas, deriva do objeto e é, ao mesmo tempo, independente dele, não admitindo uma conceituação universal, pois tem "aspectos constantes e aspectos variáveis", que se relacionam mais com aquilo que 
é de interesse do preconceituoso, dentre as diversas representações que lhes são atribuídas (Crochik, 1997). O indivíduo preconceituoso fecha-se dogmaticamente em determinadas opiniões, sendo assim impedido de ter algum conhecimento sobre o objeto que o faria rever suas posições e, assim, ultrapassar o juízo provisório. O diferente estigmatizado evoca lembranças que quer negar, e mesmo nos momentos em que se torna possível a convivência é convencido da inconveniência de mostrar o que pode parecer identificação com “um outro”. Esse sentimento ambíguo, de que nos fala Crochik (1997), é que determina o afastamento, o que impede o contato pelo medo de que, com a identificação, sejamos analogamente humilhados. Vem também do medo do diferente, do que não é conhecido, podendo ser transformado em inferioridade, desigualdade e exclusão. O preconceituoso afasta esse "outro", porque ele põe em perigo sua estabilidade psíquica. Assim, o preconceito cumpre também uma função social: construir o diferente como culpado pelos males e inseguranças daqueles que são iguais.

A ação irrefletida, a "economia do esforço intelectual" (Crochik, 1997), são as características do preconceito como predisposição para a ação de discriminação. A agressão é encaminhada para o alvo errado, por não se ter a consciência de que são os princípios sociais impregnados nas relações entre os homens e nas formas de trabalho que devem ser combatidos e não suas vítimas. O preconceito é, portanto, contrário às diferenças, levando o preconceituoso a uma outra identificação, como esclarecem Horkheimer e Adorno (1973, p. 179): "Para que se sintam alguém, essas pessoas têm necessidade de se identificar com a ordem estabelecida e essa identificação faz-se com tanto mais agrado quanto mais inflexível e poderosa for essa ordem. E dessa forma as particularidades são destroçadas em função da totalidade".

No ensaio "Educação após Auschwitz", Adorno (1995b, p. 122) afirma que "a violência contra os fracos se dirige, principalmente, contra os que são considerados fracos". A lembrança da fragilidade humana, da diferença compreendida como obstáculo à inserção funcional na sociedade, determina a prática da negação social. Por outro lado, a renúncia de autonomia por parte dos adaptados é algo que fica internalizado, retornando na forma de agressão e discriminação àqueles que demonstram algum tipo de resistência. É o caso dos alunos que são tipificados como indisciplinados ou com distúrbios de comportamento. A esse respeito, diz Adorno: “A pressão do geral dominante, sobre tudo que é particular, os homens individualmente e as instituições singulares, tem uma tendência a destroçar o particular e o individual, juntamente com seu potencial de resistência" (idem, ibidem).

\section{Preconceito, deficiência, experiência}

$\mathrm{O}$ preconceito às pessoas com deficiência configura-se como um mecanismo de negação social, uma vez que suas diferenças são ressaltadas como uma falta, carência ou impossibilidade. A deficiência inscreve no próprio corpo do indivíduo seu caráter particular. O corpo deficiente é insuficiente para uma sociedade que demanda dele o uso intensivo que leva ao desgaste físico, resultado do trabalho subserviente; ou para a construção de uma corporeidade que objetiva meramente o controle e a correção, em função de uma estética corporal hegemônica, com interesses econômicos, cuja matéria-prima/corpo é comparável a qualquer mercadoria que gera lucro. A estrutura funcional da sociedade demanda pessoas fortes, que tenham um corpo "saudável", que sejam eficientes para competir no mercado de trabalho. $\mathrm{O}$ corpo fora de ordem, a sensibilidade dos fracos, é um obstáculo para a produção. Os considerados fortes sentem-se ameaçados pela lembrança da fragilidade, factível, conquanto se é humano.

As pessoas com deficiência causam estranheza num primeiro contato, que pode manter-se ao longo do tempo a depender do tipo de interação e dos componentes dessa relação. O preconceito emerge como um comportamento pessoal, porém não pode ser atribuído apenas ao indivíduo, posto que não se restringe a exercer uma função irracional da personalidade. 
Pode ocorrer a reação mimética de que fala Crochik (1997), que consiste num imobilismo de impacto por parte do preconceituoso, semelhante ao que acontece com alguns animais ao serem perseguidos. Por serem as motivações inconscientes decisivas para a formação do preconceito, é pertinente uma reflexão que resulte na explicitação das causas de tal estranheza.

O corpo marcado pela deficiência, por ser disforme ou fora dos padrões, lembra a imperfeição humana. Como nossa sociedade cultua o corpo útil e aparentemente saudável, aqueles que portam uma deficiência lembram a fragilidade que se quer negar. Não os aceitamos porque não queremos que eles sejam como nós, pois assim nos igualaríamos. É como se eles nos remetessem a uma situação de inferioridade. Tê-los em nosso convívio funcionaria como um espelho que nos lembra que também poderíamos ser como eles. Esse potencial, que é real, em vista das trágicas mudanças que nos podem ocorrer, é que nos faz frágeis, uma vez que queremos ser sempre completos e constantes. O que também parece perturbar nos contatos com pessoas com deficiência é o fato de não sabermos como lidar com elas, posto que a previsibilidade é uma forte característica das relações sociais da contemporaneidade. $\mathrm{O}$ estigma, por ser uma marca, um rótulo, é o que mais evidencia, possibilitando a identificação. Quando passamos a reconhecer alguém pelo rótulo, o relacionamento passa a ser com este, não com o indivíduo. E, assim, idealizamos uma vida particular dos cegos, dos surdos, que explica todos os seus comportamentos de uma forma inflexível, por exemplo: ele age assim porque é cego. Nesse processo de rotulação, o indivíduo estigmatizado incorpora determinadas representações, passa a identificar-se com uma tipificação que o nega como indivíduo. Essas pessoas passam a ser percebidas, a princípio, por essa diferença negativa, o que irá indicar fortemente como elas irão comportar-se. Glat (1991, p. 9) expressa esta particularidade das interações como um "fabuloso teatro":

Esse rótulo tem uma dupla função: ao mesmo tempo que serve de ingresso numerado, indicando qual o lugar onde ele tem direito de sentar no "Teatro da Vida", determina também o script que o indivíduo terá que representar enquanto ator nesse teatro!... Assim, não só ele passa a agir segundo os padrões esperados pelo papel (os únicos que lhe foram ensinados), como os outros atores também contracenam com ele enquanto pessoa estigmatizada reforçando ainda mais esse papel.

Nesse ambiente, as pessoas constituem-se de forma defensiva para evitar maior sofrimento. Muitas vezes as pessoas com deficiência aceitam e até defendem encaminhamentos que negam as suas possibilidades de escolha e atuação, reforçando ações beneficentes e assistencialistas que têm a incapacidade como princípio. Nesse sentido, todos nós, e não apenas as pessoas com deficiência, nos distanciamos cada vez mais da autonomia e da possibilidade de diferenciação, restando apenas a adaptação à situação existente, que constitui um esforço para aceitar a mentira necessária para a sobrevivência ou autopreservação, porém extremamente onerosa em termos de energia que poderia ser utilizada para se contrapor a ela. Esse mecanismo é possível devido à consciência coisificada, que se orienta pelo princípio da adaptação.

A condição das pessoas com deficiência é um terreno fértil para o preconceito em razão de um distanciamento em relação aos padrões físicos e/ou intelectuais que se definem em função do que se considera ausência, falta ou impossibilidade. Fixa-se apenas num aspecto ou atributo da pessoa, tornando a diferença uma exceção. Vash (1988) descreve três tendências para explicar a desvalorização das pessoas com deficiência: a consideração do preconceito como algo biologicamente determinado, o questionamento psicossocial, segundo o qual no plano das relações sociais os diferentes são menos tolerados, e a tendência que a autora denomina político-econômica, em que ser deficiente resulta em mais custos para o sistema social, que envolvem desde a família até a sociedade mais ampla.

Amaral (1998, p. 16-17) descreve três versões do preconceito dirigido a essas pessoas: chama de "generalização indevida" o juízo que transforma a 
condição de limitação específica de uma pessoa em totalidade, ou seja, ela torna-se deficiente por ter uma deficiência; "correlação linear" é a disposição para elaborar relações do tipo "se...então", simplificando de forma demasiada o raciocínio, consolidando o preconceito pela economia do esforço intelectual. E o "contágio osmótico" é o temor do contato e do convívio, numa espécie de recusa em ser visto como um deficiente. Inúmeras são as formas pelas quais o preconceito às pessoas com deficiência se constitui e é reforçado: pela educação escolar, pela mídia, nas relações familiares, pelo trabalho, pela literatura, entre outras.

Vivemos atualmente uma hiperexposição do corpo como produto, algo passível de elaboração e reconstrução, tendo como referência uma cartografia corporal com toques de sedução e negação dos traços do tempo. Sabemos que os meios de comunicação, por si sós, não determinam modelos estéticos corporais; são, porém, um poderoso braço ideológico de divulgação e convencimento dos padrões selecionados e acionados pela indústria. A produção televisiva no Brasil, reconhecidamente intensa, e uma população vulnerável e receptiva aos seus produtos, devido ao baixo nível de escolaridade e rendimento, são componentes fundamentais para a legitimação de "necessidades" e formas de satisfazê-las. A não-visibilidade das pessoas com deficiência no âmbito das relações sociais é o que determina sua ausência na mídia, posto que, na lógica da indústria cultural, não existem necessidades a elas relacionadas. Sendo assim, o silêncio sobre elas é anterior e exterior aos veículos de comunicação, e suas poucas aparições ficam restritas às campanhas publicitárias para arrecadação de recursos para as instituições filantrópicas que veiculam mensagens que as representam como vítimas ou como heróis.

A televisão, como um dos mais poderosos veículos de comunicação atualmente, forja a hegemonia de valores por meio dos programas de entretenimento, jornalismo e publicidade, tornando-os referência para milhões de consumidores. Sua mensagem, que alia discurso e imagem, combina, de forma híbrida, diversos roteiros e mensagens sobre o "ser deficiente", mesmo sem freqüentemente mostrá-lo, veiculando estereótipos diversos a partir de matérias de suposta prestação de serviços, informações imprecisas e errôneas, personagens caricatos em que predominam os discursos beneficentes, preconceituosos e sensacionalistas. $\mathrm{O}$ enfoque dado pela mídia às notícias que envolvem pessoas com deficiência as coloca numa posição de vítima, com ênfase na impotência e dependência, revigorando a discriminação. A publicação Mídia e deficiência, coordenada pela Agência de Notícias dos Direitos da Infância (ANDI) e Fundação Banco do Brasil, assinala:

Mesmo quando existe interesse e desejo de realizar uma boa cobertura, os jornalistas se deparam com a desinformação sobre aspectos educacionais, jurídicos, técnicos, médicos, éticos e políticos. [...] Não há preocupação em divulgar serviços relacionados à melhora da qualidade de vida de crianças, adolescentes, adultos e idosos com deficiência. Mais de $60 \%$ das matérias analisadas só ouviram uma fonte. Na maioria delas tampouco há clareza sobre os direitos desses cidadãos. E quase sempre a entrada da questão na pauta dos meios depende de eventos organizados por entidades interessadas na causa ou da agenda de órgãos oficiais. (Vivarta, 2003, p. 35)

Além disso, não se percebe uma atitude de pressão, por parte dos meios de comunicação, para que os órgãos públicos prestem serviços a esse segmento da população, na medida em que veiculam matérias que envolvem muito mais as entidades filantrópicas e suas realizações, deixando no esquecimento os órgãos do Estado responsáveis por políticas públicas na área, a exemplo da Coordenadoria Nacional para a Integração da Pessoa Portadora de Deficiência (CORDE) e a Secretaria de Educação Especial (SEESP), ou ainda o projeto de lei de autoria do senador Paulo Paim, que busca estabelecer mecanismos e ações legais para assegurar os plenos direitos dessas pessoas.

Freqüentemente, das pessoas com deficiência é retirada a possibilidade de constituírem-se como sujeitos, porque lhes são atribuídas qualidades especiais 
que tornam natural a sua condição de "pessoa deficiente" e, como tal, sem necessidades cognitivas, de interações sociais ou de aprendizagem. Esse processo de "sublimação" é responsável pelo tratamento assistencialista prestado por instituições especializadas e voluntários que impregnam suas práticas de um amor caridoso justificado por um entendimento de que essas pessoas são naturalmente boas, carentes e puras. É perceptível o sentimento de gratidão que têm essas pessoas pelos "voluntários". Uma certa comiseração se instala nos interstícios da relação "deficiente/voluntário", em que ambos se autocompadecem de suas condições. O "deficiente" torna-se "grato pela atenção dispensada", expressando sua carência e levando seu "agente voluntário" a assumir-se como excepcionalmente bom, solidário e generoso. A filantropia não abarca somente os deficientes, mas os desvalidos.

$\mathrm{O}$ atual discurso pedagógico, tardiamente no Brasil, recorre a uma perspectiva de acolhimento das diferenças por meio da orientação inclusivista, no intuito de que todos os alunos estudem num ambiente único e que o foco da aprendizagem não esteja no aluno, mas na classe. Embora tal orientação tenha se constituído em uma tendência para os encaminhamentos das ações sociais em atendimento às reivindicações por inclusão social de variados matizes (o movimento antimanicomial, os movimentos dos idosos ou terceira idade etc.), nas últimas décadas, tem sido na área de educação que a denominação mais intensivamente aderiu. Falar em movimento inclusivista hoje é compreendido como a educação de crianças e jovens com necessidades especiais em escolas regulares. Mas o apelo para a convivência com as diferenças - tema, aliás, recorrente na literatura educacional faz um amplo eco exatamente porque a convivência humana é ainda marcada por conflitos em função dos preconceitos e das discriminações de gênero, de etnia, de religião, entre outros.

A observação mais atenta da ambiência da escola regular, onde estão alguns poucos alunos que têm deficiência, é nitidamente perturbadora: percebe-se que esses alunos tentam adaptar-se, acessando o po- tencial de que dispõem dentro das suas possibilidades num ambiente misturado e rico para interações, mas que por si só, sem a atenção sobre suas necessidades especiais, não possibilita experiências de formação e não aproveita as possibilidades, deixandoos limitados a uma participação precária no que se refere à socialização e à aprendizagem. Ora, essas experiências têm sido negadas na sociedade atual, que impõe o conhecimento coisificado e descontextualizado, pronto para ser utilizado. $\mathrm{O}$ desencantamento do mundo tornou-se um paradoxo, pois abstraiu das experiências a aproximação com as imagens e formas, substituídas pelo discurso elaborado em que o conteúdo é representado a partir de recursos tecnológicos, o que favorece um outro encantamento que nada tem de racional.

Se entendermos experiência como uma atividade auto-reflexiva proporcionada pela apreensão da realidade nas suas variadas manifestações, sem essa aptidão se exercita a esperteza necessária no mundo de "fora", que se constitui na astúcia para sobreviver em ambientes considerados hostis.

$\mathrm{O}$ que, de fato, se torna evidente é a dificuldade dos alunos, com ou sem deficiência, para constituírem experiências, tal como a entende Adorno (1996, p. 405): "a continuidade da consciência em que perdura o ainda não existente e em que o exercício e a associação fundamentam uma tradição no indivíduo". O que se vê é a apreensão de informações que prescindem de contato e aproximação, não permitindo encontros, nem trocas, nem elaborações do vivido. A imagem feita pelo autor para esse estado de inércia é muito reveladora: como os viajantes que, do trem, denominam lugares por onde passaram "como um raio", porém tendo sempre uma resposta para qualquer pergunta sobre seus itinerários. Vivemos em ambientes onde quase nunca encontramos pessoas com deficiências, devido aos diversos impedimentos que os tornam inacessíveis: barreiras arquitetônicas, ausência de sinalizações, transportes inadequados etc., apesar dos diversos dispositivos legais existentes no país para garantia dos direitos sociais. A presença desses alunos na escola causa uma natural curiosida- 
de sobre suas vidas, seu cotidiano, suas formas de percepção, que até pode motivar uma aproximação ou convivência.

O afastamento dá-se pelo medo da experiência e das relações espontâneas que permitem a elaboração do medo e do desejo. Dessa forma, vivemos aquém do que potencialmente podemos ser, enrijecidos como o caracol que recolhe suas antenas num movimento de bloqueio ante o perigo premeditado. ${ }^{1}$ Se este é real, mediante os condicionamentos e as relações sociais coisificadas, cabe forjar alternativas de liberdade e felicidade. A apreensão dos objetos, sendo operada de forma dissociada, impõe o divórcio entre o pensar e o sentir, e assim vivemos impassíveis diante do mundo, incapacitados para as relações mais livres. Essa cisão só autoriza a aproximação com os simulacros, no máximo experiências incompletas, carentes de reflexão e atividade.

A identificação só é possível por meio da convivência, na medida em que enfatiza o que não é igual e, ao mesmo tempo, ressalta a idéia de ser igual na diferença, desafiando os receios do estranhamento e do medo. A desvalorização e o distanciamento da experiência podem explicar-se, também, porque queremos ver os resultados, subtraindo-a, tal como demandam as relações contemporâneas baseadas no imediatismo e automatismo. Experiência é "a continuidade da consciência em que perdura o ainda não existente e em que o exercício e a associação fundamentam uma tradição no indivíduo" (Adorno, 1996, p. 405). O autor diz ainda, em outra passagem do mesmo texto, que: "Quem dispensa a continuidade do juízo e da experiência se vê provido por tais sistemas, apenas com esquemas para subjugar a realidade. De fato, não alcançam a realidade, mas contentam-se em compensar o medo diante do incompreendido" (idem, ibidem). A experiência desafia os medos do

1 A imagem do caracol, apresentada por Horkheimer e Adorno (1985, p. 239), indica a gênese do ensimesmamento, pois sempre que o pequeno animal recolhe as antenas inibe também sua espontaneidade e curiosidade, tão necessárias para a experiência. contato com o diferente, medo de ser discriminado, de experimentar algo não habitual, medo de arriscarse ao erro. E é o medo que impede o confronto com o sofrimento, que se torna mais resistente se não nos colocamos diante dele. "Quando o medo não é reprimido, quando permitimos ter realmente tanto medo quanto a realidade exige, então justamente por essa via desaparecerá, provavelmente, grande parte dos efeitos deletérios do medo inconsciente e reprimido" (Adorno, 1995a, p. 129).

\section{Diferença e tolerância}

A discussão sobre as diferenças demanda uma concepção de igualdade para que se possa pensar a sua afirmação na sociedade. A igualdade pede mais que o simples reconhecimento do outro, que, assim sendo, cabe enfatizar, se limita à tolerância, já que essa posição não permite que cada indivíduo se constitua a partir de sua experiência, sem se reduzir a um insumo da racionalidade instrumental. O sentimento que mais se manifesta nos tempos atuais é a tolerância como limite do aceitável, quando já poderíamos nos manifestar com solidariedade em relação ao diferente, por ser a diferença a essência de todos nós. $\mathrm{O}$ "distinto" é mantido na sociedade dentro do parâmetro do tolerável ou integrado, e a indiferença é o que resta como condição de sobrevivência, retratando a frieza.

A tolerância vem sendo afirmada como um princípio instaurador para a convivência entre as pessoas diferentes. Um breve levantamento sobre o termo indica que seu aparecimento se dá nos idos do século XIV, nos escritos do filósofo Guillermo de Ockham, como afirmação da possibilidade de salvação sem a fé na religião canônica. É uma virtude em prol da convivência harmoniosa e pacífica, tendo sido colocada como um princípio fundamental na vida civil a partir da Reforma, "nas lutas que contrapuseram, uma à outra, as várias partes da cristandade" (Abbagnano, 1970). Segundo Cardoso ([s.d.]), a Carta acerca da tolerância de John Locke, escrita em 1689, e o Tratado sobre a tolerância de Voltaire, publicado em 1763, 
são importantes referências para a compreensão do sentido moderno de tolerância, pois esclarecem seus elementos fundantes na idéia da diversidade e da identidade. $\mathrm{O}$ autor sintetiza tais referentes da seguinte forma:

A Carta de Locke e o Tratado de Voltaire parecem evidenciar duas linhas de fundamentação filosófica do valor tolerância na modernidade. A primeira, o empirismo, vê na cultura, e não na natureza humana, as características fundamentais do ser humano. Não existe uma sociedade humana única, pois muitas são as culturas historicamente construídas. Seguindo a tradição cética, o empirismo afasta-se da verdade universal, enquanto identidade metafísica, para buscar na necessidade da convivência social com o diferente a justificativa para o comportamento tolerante. Uma sociedade racionalmente evoluída é aquela cujas bases fundam-se em um contrato de convivência, onde todos são livres para expressarem suas posições, tendo assegurado o bem comum. Na segunda vertente, fundada no racionalismo, o valor tolerância é construído sobre as bases da tradição metafísica. Em outras palavras, Voltaire extrai da própria natureza do ser humano os argumentos a favor da boa convivência. Não se trata de aceitar o outro pelo respeito àquilo que temos de diferente: a cultura ou as idiossincrasias, mas por nossa identificação mútua como seres humanos. (Cardoso, [s.d.], p. 1)

A partir do século XIX, a tolerância já estava totalmente desvinculada do seu sentido religioso, porém com um significado tal como ainda encontramos nos dicionários: tolerar como consentimento tácito de suportar ou agüentar, revelando a ideologia do colonizador no seu projeto de dominação. Nos últimos anos, tolerância tornou-se quase uma palavra de ordem nos diversos eventos e publicações, indicando o exercício necessário em favor das diferenças e contra qualquer cerceamento do pensamento, ou uma espécie de valoração positiva que se invoca em momentos de conflitos. Em 1995, na sua Conferência Geral em Paris, a Organização das Nações Unidas para a Educação, a Ciência e a Cultura (UNESCO) aprovou a Declaração de Princípios sobre a Tolerância, e em
1997 realizou na Sorbonne o Foro Internacional sobre a Intolerância, que resultou na publicação, pela Academia Universal de Cultura, do livro A intolerância, com textos de Umberto Eco, Paul Ricoeur e Jacques Le Goff, entre outros.

Entretanto, é preciso lembrar que, numa sociedade que convive com desigualdades intensas, a tolerância parece seguir sempre um movimento linear, de mão única. Recorrer a esse argumento, iludindo-se com a pretensa igualdade de todos numa sociedade injusta, atesta poucas possibilidades de convencimento ante uma "igualdade abstrata"; em dado momento, pode ser vista com uma postura de superioridade, e não como atitude transitória em direção ao verdadeiro reconhecimento: "eu te suporto, porque sou generoso". Torna-se uma aceitação com reticências, uma licença condescendente às particularidades, como se fosse uma deferência ao outro. Com esse entendimento, existe um limite para tolerar-se, e a fronteira para isso está no que pode ser aceitável ou o que não mais é considerado saudável. A intolerância seria uma forma de imputar culpa aos que não souberam controlar os riscos que os tornaram diferentes. Ora, como existe um valor para um padrão de beleza, saúde, qualidade de vida, autocontrole, entre outros, os que se distanciam desses alvos devem ser punidos por tal negligência. A intolerância torna-se uma agressividade irracional contra formas de ser e estilos de vida contrários aos que se convencionou, por escolha ou (pseudo)formação, como absolutamente verdadeiros. Rouanet (2003, p. 11) afirma que tolerância deve ser um caminho, não um fim: “A implantação de uma cultura da tolerância é um cessar-fogo na guerra das diferenças, mas ainda não é a paz. As diferenças não devem ser apenas toleradas, porque do contrário elas se reduziriam a um sistema de guetos estanques, que se comunicariam apenas no espaço público".

Marcuse (1970, p. 102), em ensaio sobre o significado de tolerância na sociedade estadunidense, posiciona-se em favor de uma tolerância partidária, pois que para ser um fim em si mesma requer uma condição de universalidade, sob pena de servir "à causa da opressão". O autor dá um exemplo de tolerân- 
cia desumana, ainda que presumivelmente pautada no que se considera equivalente à objetividade:

[...] se um locutor de rádio descreve a tortura e assassinato de propagandistas de direitos civis no mesmo tom sem emoção que usa para descrever as flutuações do mercado ou as condições do tempo, ou com a mesma grande emoção com que lê os comerciais, então tal objetividade é espúria - mais ainda, ofende a humanidade e à verdade porque se mostra calmo onde deveria ter-se enfurecido, e porque se abstém de acusar quando a acusação ressalta dos próprios fatos. [...] Se a objetividade tem algo a ver com a verdade, e se a verdade é algo mais do que uma questão de lógica ou ciência, então esse tipo de objetividade é falso, e essa espécie de tolerância é desumana.

Marcuse deixa clara a contradição entre a estrutura social e política da sociedade e o princípio da tolerância que, sendo falsa e abstrata, mais obsta do que promove a mudança ou desempenha a função pela qual foi forjada pelos protagonistas liberais. Já Matos ([s.d.]) chama a atenção para um outro sentido de tolerância que contraria a concepção conciliadora, quando entendida como combate: "Neste caso, tolerar é esforço para desfazer ortodoxias, revelar a dessemelhança no que parece homogêneo, a fim de que um possa ir ao encontro do Outro" (p. 1).

O desejo de individuação e diferenciação não se define por um simples "ideal do eu". Mais que isso, pressupõe condições sociais para que o reconhecimento do outro ultrapasse a simples relação interpessoal. Mesmo a idéia de igualdade pela distribuição de renda, por si só, não garante o princípio de respeito às diferenças. Assim, igualdade e diferença são conceitos não excludentes, mas interdependentes, que mantêm permanente interação.

A igualdade na perspectiva da democracia liberal afirma-se pelo direito de todos perante a lei, considerando que todos são livres e obedecem às mesmas leis. Sua contradição efetiva está em que, como princípio, se contrapõe à desigualdade real no que se refere à apropriação dos bens, posicionamento no trabalho e distribuição material e espiritual dos produ- tos da cultura. Nesse sentido, as diferenças tornam-se desigualdades nas quais os indivíduos são negados entre os que se consideram iguais. É pertinente considerar a produção social dessa diferença, que resulta em atitudes, preconceitos, estereótipos e estigmatização, posicionando socialmente aqueles considerados diferentes como cidadãos de segunda categoria.

A convivência na diversidade não significa assumir a posição de espectador passivo e tolerante. O pressuposto essencial está em admitir que cada indivíduo tem direito de combinar experiências pessoais de vida com a coletividade, imprimindo, todavia, uma identidade particular que constitui sua individualidade. É importante reafirmar que esse direito se encontra impedido de ser realizado na atual sociedade, que dispensa as singularidades individuais.

A conveniência do discurso da diferença expressa-se pela necessidade de pacificação social naquilo que inquieta. É necessário harmonizar as relações com o outro marginal e estranho para fortalecer a segurança e garantir minimamente a "paz social". Impedir o conflito e a violência das relações sem superar as causas que assim as configuram apenas forja uma aparência de sociedade acolhedora e democrática, pois que a essência do conflito irracional não é superada. Este tem sido o encaminhamento dado pela mídia, por meio de peças publicitárias rentáveis, quando veicula mensagens mitigadoras das relações multiculturais, convertendo-as em causas nobres, para assim legitimar socialmente a convivência tolerante. É a ideologia prestando-se à defesa dos ideais liberais de igualdade e fraternidade ao que é permitido na sociedade atual. Os alinhamentos propostos pelos mecanismos ideológicos criam necessidades de consumo e de comportamentos sedutores para um projeto exterior aos indivíduos e, por assim ser, não exercem a liberdade e a autonomia. Na medida em que a pulsão pela vida está enfraquecida, o risco do impulso destrutivo é uma perspectiva real de prevalência da barbárie. Nesse processo, a ideologia revela, não mais oculta, levando as pessoas a gastarem muito da energia que têm para esconder a percepção do horror. 
Essa possibilidade custosa de que falam os autores não pode ser contestada, pois que os processos de individuação e indiferenciação são movimentos de tensão e conflito subordinados às relações de poder. Porém, como afirma Zuin (1999, p. 118), "o não-presente não pode e não deve se transformar num ausente". Falar que a individuação é um projeto inviável nesta sociedade não indica a impossibilidade de nela haver confrontos e conflitos que podem, pela crítica imanente, desmascarar o caráter afirmativo do real a partir da leitura do que é silenciado.

O que ora se apresenta na sociedade contemporânea, vinda dos movimentos sociais e por parte dos intelectuais que se põem em favor de um projeto de humanização das relações sociais, é uma clara intenção de criticar todo tipo de segregação mantenedora da menoridade e heteronomia de seus membros. Se antes esse era um fenômeno justificado pela carência de condições objetivas para superar tal situação, hoje não é mais acolhido como argumento racional. $\mathrm{O}$ entendimento sobre diferenças como um componente da individualidade remete-nos aos questionamentos sobre sua possibilidade nesta sociedade, em que as relações continuam sendo de domínio e expropriação que mais respondem a uma sobrevivência irracional. É importante reafirmar a dependência mútua da sociedade e do indivíduo, para evitar o entendimento dessa reciprocidade como uma abstração, como se fosse um conceito puro. O indivíduo não é um ser natural que se emancipa dentro dos limites de si mesmo, uma vez que não é apenas uma entidade biológica. A autodeterminação ocorre na medida em que, tomando consciência do mundo, adquire consciência de si. Assim, o indivíduo concretiza-se na sociedade e por meio dela. As limitações para sua constituição pelos processos formativos da atual sociedade, contudo, retiram a força da individuação, reforçando a não-diferenciação, que é a outra face do processo de socialização.

\section{Referências bibliográficas}

ABBAGNANO, Nicolas. Dicionário de filosofia. São Paulo: Mestre Jou, 1970.
ADORNO, Theodor W. Educação após Auschwitz. In: ADORNO, Theodor W. Palavras e sinais: modelos críticos. 2. ed. Petrópolis: Vozes, 1995a. p.119-138.

Tabus que pairam sobre a profissão de ensinar. In:

ADORNO, Theodor W. Palavras e sinais: modelos críticos. 2. ed. Petrópolis: Vozes, 1995b. p. 83-103.

. Teoria da semicultura. Educação e Sociedade, Campinas, CEDES, n. 56, p. 389-411, 1996.

AMARAL, Lígia. Sobre crocodilos e avestruzes: falando de diferenças físicas, preconceitos e sua superação. In: AQUINO, Júlio G. (Org.). Diferenças e preconceitos. São Paulo: Summus, 1998. p.11-30.

CARDOSO, Clodoaldo Meneguello. Tolerância: um valor ético para o século XXI, [s.d]. Disponível em: <www.faac.unesp.be/pesquisa/ tolerancia/texto_tolerancia_cardoso >. Acesso em: 30 ago. 2003.

CROCHIK, J. Leon. Aspectos que permitem a segregação na escola pública. In: CONSELHO REGIONAL DE PSICOLOGIA. Educação especial em debate. São Paulo: Casa do Psicólogo, 1996. p. 13-22.

Preconceito. Indivíduo e cultura. São Paulo: Robe, 1997.

GLAT, Rosana. Inclusão total: mais uma utopia? Revista Integração, Brasília, MEC/SEESP, ano 8, n. 20, p. 26-28, 1991.

HORKHEIMER, Max; ADORNO, Theodor W. Elementos do antisemitismo. In: ADORNO, Theodor; HORKHEIMER, Max (Orgs.). Dialética do esclarecimento. Rio de Janeiro: Jorge Zahar Editor, 1985.

Temas básicos de sociologia. São Paulo: Cultrix, 1973.

MARCUSE, Herbert. Tolerância repressiva. In: WOLFF, Robert Paul; MOORE JR., Barrington; MARCUSE, Herbert. Crítica da tolerância pura. Rio de Janeiro: Zahar, 1970. p.87-126.

MATOS, Olgária. Sociedade: tolerância, confiança, amizade, [s.d.]. Disponível em: <www.culturabrasil.pro.br/direitoshumanos2.htm>. Acesso em: 6 mar. 2004.

ROUANET, Sérgio Paulo. O Eros da diferença. Folha de S. Paulo, São Paulo, 9 fev. 2003. Caderno Mais!, p. 11.

VASH, Carolyn L. Enfrentando a deficiência. São Paulo: Pioneira; Ed. da Universidade de São Paulo, 1988.

VIVARTA, Veet. Mídia e deficiência. Brasília: ANDI; Fundação Banco do Brasil, 2003.

ZUIN, Antonio. Indústria cultural e educação. Campinas: Autores Associados, 1999. 
LUCIENE M. DA SILVA, doutora em educação pela Pontifícia Universidade Católica de São Paulo, é professora da Universidade do Estado da Bahia, atuando no Curso de Graduação em Pedagogia e no Programa de Pós-Graduação Educação e Contemporaneidade da mesma universidade. Publicações mais importantes: com FALSARELLA, Ana Maria. Preconceito na escola inclusiva (Presença Pedagógica, Belo Horizonte, Dimensão, v. 8, n. 46, p. 96-106, jul./ago. 2002); com OLAVO, Antonio; PEREIRA, Dirceu de Socorro; GUERRA FILHO, Sérgio. Quilombos da Bahia-Manual Pedagógico (Salvador: Portfolium,
2005); Apontamentos sobre as contradições da questão deficiência e trabalho (In: ENCONTRO MINEIRO DE PSICOLOGIA SOCIAL DAABRAPSO, 14., 2005, Belo Horizonte. Anais... Belo Horizonte, 2005. 1 CD-ROM). Pesquisa em desenvolvimento: "Um estudo sobre o movimento em defesa dos direitos das pessoas com deficiência: a atuação para a inclusão". E-mail: luciene@portfolium.com.br

Recebido em janeiro de 2006 Aprovado em maio de 2006 
de que demanda dele o uso intensivo que leva ao desgaste físico, resultado do trabalho subserviente; ou para uma construção de corporeidade que objetiva meramente o controle e a correção, em função de uma estética corporal hegemônica, com interesses econômicos. Nesse sentido, todos nós nos distanciamos cada vez mais da autonomia e da possibilidade de diferenciação, restando apenas a adaptação à situação existente, que se constitui em um esforço para aceitar a mentira necessária para a sobrevivência ou autopreservação.

Palavras-chave: Diferença; preconceito; inclusão; deficiência; educação especial

The uneasiness caused by disability: discrimination and experience

This text discusses the relationship between discrimination and disability. We take as fundamental references the studies carried out by T. Adorno and M. Horkheimer on discrimination, as well as the contribution of such authors as Ligia Amaral and José Leon Crochik, for whom discrimination against disabled people is understood as a mechanism of social negation, since their differences are emphasized as an absence, need or inability.

Luciene M. da Silva Disability carves on the very body of the individual its specific character. The disabled body is not sufficient for a society that requires its intensive use leading to physical wear which is a result of subservient work; or for the construction of a corporeity that has in view mere control and correction, in terms of a hegemonic corporal aesthetics with economic interests. In this sense, we all are more and more distant from the autonomy and from the possibility of differentiation, remaining adaptation alone to the existing situation which constitutes an attempt to accept the lie necessary for survival or self-preservation.

Key words: difference; discrimination; inclusion; disability; special education 
El desconocimiento causado por la deficiencia: prejuicio y experiencia

Se discute las relaciones entre prejuicio y deficiencia. Tomo como referencia fundamental los estudios de T. Adorno y M. Horkheimer sobre prejuicio, además de las contribuciones de autores como Ligia Amaral y José Leon Crochik. Para ellos el prejuicio a las personas con deficiencia se configura como un mecanismo de negación social, una vez. que sus diferencias son destacadas como una falta, carencia o imposibilidad. La diferencia inscribe en el propio cuerpo del individuo su carácter particular. El cuerpo deficiente es insuficiente para una sociedad que demanda de él el uso intensivo, que lo lleva al desgaste físico, resultado del trabajo subsirviente; o para una construcción corporal cuyo objetivo es meramente el control y corrección, en función de una estética de supremacía del cuerpo, con intereses económicos. En este sentido, todos nosotros nos distanciamos cada vez más de la autonomía y de la posibilidad de diferenciación, restándonos apenas la adaptación a la situación existente, que se constituye en un esfuerzo para aceptar la mentira necesaria para sobrevivir o para la autoprotección. Palabras claves: diferencia; prejuicio; inclusión; deficiencia; educación especial 